\title{
Orthorexia nervosa and obsessive-compulsive behavior among college students in the United States
}

\author{
Christine B. Costa*, Kholoud Hardan-Khalil \\ School of Nursing, California State University, Long Beach, California, United States
}

Received: August 22, 2018

Accepted: October 10, 2018

Online Published: October 15, 2018

DOI: $10.5430 /$ jnep.v9n2p67

URL: https://doi.org/10.5430/jnep.v9n2p67

\begin{abstract}
Background/Objective: Orthorexia nervosa (ON) is a disordered eating pattern and obsessive-compulsive disorder (OCD) is an anxiety condition. Although ON shares many similarities with OCD, their relationship remains unclear. The objective of this study was to investigate the prevalence of both ON behaviors and OCD behaviors and whether or not an association between ON behaviors and OCD behaviors exist among college/university students in the United States.

Methods: Using a cross-sectional, descriptive research design, a convenience sample of 270 college undergraduate students provided data using self-administered questionnaires: ORTO-15 to detect orthorexia behaviors and Obsessive-Compulsive Inventory-Revised (OCI-R) to detect obsessive-compulsive behaviors. Additionally, the participants completed a demographic questionnaire designed by the authors. Chi square, Pearson's correlation coefficient and analysis of variance evaluated the variables of interest using a significance level of .05 .

Results: The prevalence rate for orthorexia nervosa behaviors was $37 \%$ and for obsessive-compulsive behaviors was $38.5 \%$. There was a strong negative correlation $(p<.001)$ between the scores of the ORTO-15 and the scores of the OCI-R. As orthorexia behaviors increased, obsessive-compulsive behaviors like-wise increased.

Conclusions: It was concluded that college/university students are a high-risk group for orthorexia nervosa and obsessivecompulsive behaviors. Mental health professionals who encounter clients with orthorexic tendencies are encouraged to also screen for obsessive compulsive symptomology as a comorbid problem.
\end{abstract}

Key Words: Orthorexia nervosa, ORTO-15, Disordered eating, Obsessive-compulsive, Obsessive-Compulsive InventoryRevised (OCI-R)

\section{INTRODUCTION}

The unusual eating behaviors associated with the phenomenon of orthorexia nervosa $(\mathrm{ON})$ were first reported by clinicians in 1996 and have since been described in the scientific literature. ${ }^{[1]}$ There has been ongoing debate regarding whether ON should formally be recognized as a separate psychiatric diagnosis or assimilated into the spectrum of an already established psychiatric diagnosis. A lack of consensus exists regarding acceptable definitions and diagnostic criteria for Orthorexia nervosa. $\mathrm{ON}$ has been variously defined as disordered eating behaviors characterized by excessive preoccupation with clean, healthy foods; an obsessive fixation on healthy eating; ${ }^{[2]}$ healthy eating that transforms into an unhealthy obsession with extensive time spent to plan, purchase, prepare and eat healthy foods $;^{[3]}$ a pathological approach to food related to healthiness concerns and purity of foods accompanied by intrusive food-related thoughts and unique, self-imposed food restrictions. ${ }^{[4]}$ Excessive preoccupation with healthy food choices can lead to unhealthy consequences, such as anxiety about whether or not a given

\footnotetext{
* Correspondence: Christine B. Costa; Email: Christine.costa@csulb.edu; Address: School of Nursing, California State University Long Beach, California, United States.
} 
food is truly healthy. ${ }^{[5]}$

ON has been associated with severe distress, impairment in social situations as well as maladjustments in school and work. ${ }^{[4]}$ The core symptomatology of ON centers on the perceived purity of food, the perceived healthiness of diet, and an over-concern about contamination. ${ }^{[4]}$ As a result, people with ON behaviors suffer the risk of being singled out in society by their own anxious, irreproachable beliefs about their food choices and food preparations. Frequently, orthorexic individuals will engage in self-praise for resisting temptation and will consider their clean, pure eating styles to be virtuous, wholesome, and a symbol of moral superiority. However, social attitudes toward this type of eating are ambiguous at best and can easily result in social repercussions, such as stigma. ${ }^{[3,6]}$ In other cases, these disordered eating behaviors may lead to an unwillingness to participate in social activities creating isolation, loneliness, and a diminished quality of life. ${ }^{[3]}$ People with ON tendencies, oftentimes, may not feel their food choices meet a preconceived health standard which can result in an increasingly narrow range of foods to consume and can also result in some degree of malnutrition depending on the severity of acquired restrictions. ${ }^{[7,8]}$ Preoccupation with developing an even more restrictive and healthier plan for themselves can begin to dominate their lives. ${ }^{[7]}$ People experiencing ON tendencies may be more likely to develop other mental disorders, such as obsessivecompulsive disorder, bipolar disorder, anxiety, anger and depression. $^{[3,7]}$

Prevalence estimates of orthorexia nervosa in the general population have been reported to be as low as $1 \%{ }^{[9]}$ to as high as $57.6 \%$. ${ }^{[10]}$ This wide range in prevalence is reflective, in part, of a variation of measuring instruments used by researchers. Disordered eating behaviors are reported to be prevalent among college students and college-age populations. ${ }^{[1,3,4,9,11]}$ The dietary intake among college students tends to be deficient in several ways. In general, consumption of fruits, vegetables, whole grains and fiber is low while consumption of sugar, sodium, and fat tend to be high. ${ }^{[11]}$ The transition to college life can involve higher stress, lower physical activity, monetary budgeting challenges, and new social pressures. An increasing prevalence of ON behaviors among young adults in college has been observed. ${ }^{[4]}$

ON shares some symptoms with other established disorders thus creating an overlap which can potentially obscure $\mathrm{ON}$ as a recognized psychiatric diagnosis. Anorexia nervosa $(\mathrm{AN})$, bulimia nervosa $(\mathrm{BN})$, and $\mathrm{ON}$ share abnormal eating habits, malnutrition, an exaggerated need for self-care, self-protection, and a preoccupation with food. ${ }^{[1]}$ However, a significant distinction among individuals who suffer from anorexia or bulimia is that, ON individuals are more concerned about food qualities, while the former are more concerned about food quantities. ${ }^{[8]}$

\subsection{ON and obsessive-compulsive disorder (OCD) symptom overlap}

ON also shares some of the symptoms of OCD such as, high anxiety traits, a need to control, preoccupation with contamination, repetitive thoughts and behaviors, and perfectionism. ${ }^{[4,8]}$ OCD, on the other hand, is a mental disorder in which people feel like they need to perform regularly, certain, ritualistic or routine behaviors or have certain repetitive thoughts. ${ }^{[12]}$ Increase in the number of repetitive behavior and thoughts can lead to a loss of personal productivity. OCD has been positively correlated with other disorders, such as depression, anxiety, tic disorders, eating disorders, obsessivecompulsive personality disorder, bipolar disorder and even suicidal thoughts. ${ }^{[12]}$ Moroze et al. ${ }^{[13]}$ have postulated that obsession may even be the root of orthorexia, i.e. a continuum from obsessive preoccupation with health to the distress brought on by obsessional thoughts and beliefs about food and healthy eating. ${ }^{[4,13]}$

Although significant advancements have been made in diagnosing and treating people with tendencies of both Orthorexia and OCD, there has been limited evidence regarding whether a relationship exists between the two disorders. ${ }^{[14]}$ Possible biochemical similarities have been observed that can influence thought patterns and behaviors in both ON and OCD. In a study by Murphy et al. ${ }^{[14]}$ it was determined that patients with OCD and eating disorders had higher cerebral glucose metabolism which did not allow them to effectively complete a task which required the work of the prefrontal cortex and caudate nucleus of the brain. They implied that similar neurophysiological similarities exist in OCD and orthorexia. ${ }^{[14]}$ Koven et al. ${ }^{[8]}$ suggested that a potential relationship between ON symptoms and OCD may exist when repetitive and ritualistic behaviors are focused on food. When an individual with OC tendencies gravitates towards a ritualistic checking of nutritional information and has repetitive thoughts about achieving ever-increasing healthier eating, ON symptomatology may be present. ${ }^{[8]}$

Considering that OCD and ON behaviors may exhibit similar behavioral and thinking patterns, it may be problematic to determine which is more prevalent. It has been reported that people with eating disorders, including those with orthorexia tendencies, have between an $11 \%$ to $69 \%$ higher rate of also having OCD. Additionally, those with OCD have a $10 \%$ to $17 \%$ higher rate of having eating disorders. These findings suggest that $64 \%$ of patients with symptomatic eating disorders have, at least, one more co-existing anxiety 
disorder which is frequently (41\%) OCD. ${ }^{[15]}$ Based on these investigations, it can be reasonably speculated that eating disorders, including $\mathrm{ON}$, could potentially be a part of the OCD spectrum.

Brytek-Matera $^{[16]}$ noted that while healthy diets and lifestyles are good and desirable, in some individuals these health habits can reach a point beyond normalcy and turn into obsession and preoccupation, thus clearly resembling the signs of obsessive-compulsive disorder. Accordingly, people with orthorexia tendencies can try to become so efficient with providing their bodies with what they consider is the right amount of healthy nutrients they may start to experience excess worries, stress and preoccupation with the very quality of foods. Since orthorexia symptomatology is treated similarly to obsessive-compulsive disorder, it might be closely linked to OCD. ${ }^{[16]}$ The OCD Center of $\mathrm{LA}^{[5]}$ has suggested that orthorexia can be viewed as a hybrid between an eating disorder and OCD since it shares characteristics of both disorders. As an example, similar to OCD, orthorexia comprises obsessive thoughts and behaviors, but focuses on specific diets and foods. Likewise, orthorexia has compulsive behaviors that the patient possesses in order to minimize his/her anxiety caused by the obsessive thoughts. ${ }^{[5]}$

Poyraz et al. ${ }^{[17]}$ pointed out some additional observations of how orthorexia nervosa, despite being viewed by some as a separate disordered eating behavior, shares common features in its clinical presentation with obsessive-compulsive disorder and other eating disorders. In their study among 130 patients diagnosed with different disorders, only a few had significantly different mean scores on various diagnostic related, screening tests (Padua Inventory Washington State University Revision [PI-WSUR], the ORTO-11 and the Eating Attitudes Test-40 [EAT-40]). The authors suspected that while orthorexia may share ritualistic signs with OCD, the worries that people with OCD have, may prompt them to develop "pure" diets and act as they would act if they had orthorexia tendencies. ${ }^{[17]}$

Much of the limited research regarding a potential relationship between ON tendencies and OCD has been conducted in the United States. The findings from these few studies have frequently been generalized to other anxiety and food related disorders. ${ }^{[18]}$ Scarff ${ }^{[19]}$ suggested that even though individuals with ON symptoms share the ritualistic behaviors of those with OCD leading some to consider the symptomatology co-morbid, the underlying differences between them are more prevalent than the commonalities. Individuals with both diagnoses demonstrated a need to exert control and exhibit perfectionism. According to Scarff, ${ }^{[19]}$ the one common trait between OCD and ON tendencies is anxiety.

\subsection{Objective of the study}

The debate regarding whether orthorexia nervosa is a distinct eating disorder or just part of the obsessive-compulsive disorder spectrum continues in the literature. Given the observance of some common symptomatology between $\mathrm{ON}$ tendencies and OC symptomatology described in the literature, the goals of this study were to first, assess the prevalence of orthorexia nervosa symptomatology and the prevalence of obsessive-compulsive tendencies among a young adult, college population at risk for anxiety and, second to determine whether or not an association between orthorexia nervosa tendencies and obsessive-compulsive tendencies exists among this population.

\section{MeTHODS}

\subsection{Study design}

A cross-sectional, descriptive study design using selfreported, objective surveys was used to determine the presence or absence of orthorexia tendencies and/or obsessivecompulsive symptoms among a sample of university students in the United States.

\subsection{Setting}

This study was conducted at a large, public university campus in Southern California. The university has one of the most ethnically diverse students in California, offers bachelor, masters, and, doctoral degrees and attracts students from many different countries. Data were collected between June, 2016 and November 2016.

\subsection{Participants}

Participants in this study comprised a sample of convenience, verbally recruited from undergraduate classes. The student participants did not receive any incentives for participation. Inclusion criteria consisted of the following: fluent in comprehending, reading and, writing English, matriculating at the university either fulltime or part time, at least 18 years of age, ability to access, select, and prepare their own foods for consumption. Exclusion criteria for this study were as follows: younger than 18 years of age, participants with a prior or current diagnosis of anorexia nervosa, bulimia, binge eating disorder, or obsessive-compulsive disorder, a non-matriculating student at the university. Potential participants were given a general description of the study, given the opportunity to ask questions, informed that non-participation would not be penalized in any manner, and were asked to sign an informed consent approved by the Institutional Research Board if electing to participate. The number of participants recruited was 281 . Only 270 of the questionnaire sets returned had complete responses. Eleven questionnaire sets were not complete and had to be removed from the data set. 


\subsection{Materials and procedures}

Approval from the university's Institutional Review Board (IRB) was obtained. The questionnaires were selfadministered with the exception measuring the participant's body weight. Weight was measured and recorded by a research assistant using a calibrated electronic scale. The researchers elected to measure weight because respondents have a tendency to either not know their exact weight, give a guess, or not accurately report their current weight. They were allowed to self-report height because respondents tend to know and report their accurate heights. Three student research assistants currently enrolled in an undergraduate research program at the university and one student assistant enrolled in a university food science program, were trained by the principal investigators and assisted in the data collection. Confidentiality was assured by close supervision of all phases of the study by the primary investigators, by securing all raw data in a locked drawer in the principle investigator's office and by reporting outcomes in aggregate form only. Participants were given the right to refuse to complete any question in the questionnaires. The two trained research assistants double-checked the participants' responses for completeness and then entered them into a SPSS data set.

\subsection{Study measures}

A sociodemographic survey and two test measures (one standardized and one still in the standardization process), ORTO15 and Obsessive-Compulsive Inventory-Revised (OCI-R) were used in this investigation. The sociodemographic survey was created by the principle investigators to capture the characteristics of the sample. Questions were asked about the participant's age, height, gender, ethnicity, marital status, smoking habits, alcohol consumption, diet/diet preferences, allergies and, physical activity level. From the data, body mass index (BMI) was calculated using the equation: $\mathrm{BMI}=$ weight $(\mathrm{kg}) / \mathrm{height}^{2}\left(\mathrm{~m}^{2}\right)$.

\subsubsection{ORTO-15}

Orthorexia nervosa tendencies and prevalence of attitude and behavior related to consumption of eating healthy food was assessed using the ORTO-15 measure, with a cut-off score of 40 . The ORTO-15 is the most widely accepted assessment measure utilized specifically to screen for orthorexic tendencies. ${ }^{[16]}$ Donini et al. ${ }^{[20,21]}$ is credited with developing the ORTO-15 consisting of 15 Likert scale questions (1 "never" to 4 "always") with a total scoring range of 15 to 60 . A score below 40 indicates orthorexia behaviors; the lower the score, the greater the tendencies. ${ }^{[22]}$ It is important to note that at this time, the ORTO-15 is still a partially validated measurement too ${ }^{[3,23]}$ which has some problems with internal consistency. ${ }^{[3,8,23-25]}$ However, the ORTO-15 is still the most widely accepted measuring tool to assess $\mathrm{ON}$ tendencies and prevalence at this time and was therefore, used in this study.

\subsubsection{OCI-R}

The Obsessive-Compulsive Inventory Revised (OCI-R) assesses obsessive-compulsive disorder tendencies in an individual. ${ }^{[26]}$ Obsessions and compulsions, as well as, the severity of these symptoms are measured separately. The OCI-R consists of 18 questions divided equally into six subscales; checking, hoarding, neutralizing, obsessive behaviors, ordering, and washing. The OCI-R has an acceptable internal consistency (.88 to .92 and .57 to .93 for the subscales) in clinical and non-clinical populations. ${ }^{[27,28]}$ Responses are on a 5-point Likert scale (0 "not at all" to 4 "extremely"). The OCI-R total score ranges from 0 to 72 . Using the cut off score of 20, higher scores indicate obsessive-compulsive disorder tendencies; the higher the score, the greater the tendencies.

\subsubsection{Statistical analysis}

The statistical level of significance was set at .05 and all statistical analyses were done using SPSS 24.0 IBM for Windows. Descriptive statistics were used to characterize the sample in this study. Chi square analyses were performed to determine if there was a significant association between subjects who scored less than 40 on the ON (indicating ON tendencies) and above 20 on the OCI-R (indicating OCD tendencies). Pearson's moment correlation coefficient ( $r$ ) was used to determine from among those who scored less than 40 on the ON (indicating ON tendencies) and above 20 on the OCI-R (indicating OCD tendencies), whether or not a correlation exists between the scores on the ORTO-15 and those on the OCI-R and its sub-categories (checking, hoarding, neutralizing, obsessing, ordering, and washing). Analysis of variance was done to determine if any sub-categories of the OCI-R significantly contributed to ON tendencies detected by the ORTO- 15 .

\section{RESUlts}

Due to incomplete responses to various questions from 11 participants, only 270 of the 281 respondents were included in the statistical analyses.

As shown in Table 1. The sample was over $65 \%$ Asian or Hispanic, 14\% Caucasian, 13\% African American, with the remainder reported as "Other". Of the remaining 270 respondents, $58 \%(\mathrm{~N}=157)$ were female and $42 \%(\mathrm{~N}=113)$ were male, with a mean age of 20.2, and a SD of 1.7. The typical subject in this study was: an undergraduate female student, aged 18 to 21, unmarried, regularly exercised, and, had no religious dietary restrictions or food allergies. 
Table 1. Demographic characteristics of participants by gender

\begin{tabular}{|c|c|c|c|c|c|c|}
\hline Variable & $\begin{array}{l}\text { Male } \\
(\mathrm{n}=113)\end{array}$ & $\begin{array}{l}\text { Female } \\
(\mathrm{n}=157)\end{array}$ & $\begin{array}{l}\text { Total } \\
(n=270)\end{array}$ & $\begin{array}{l}\text { Cumulative } \\
\text { Percentage }\end{array}$ & Mean & SD \\
\hline \multicolumn{7}{|l|}{ Age } \\
\hline 18 to 21 years old & 88 & 115 & 203 & 75.18 & \multirow{5}{*}{42.29} & \multirow{5}{*}{5.87} \\
\hline 22 to 25 years old & 12 & 29 & 41 & 15.19 & & \\
\hline 26 to 29 years old & 7 & 10 & 17 & 6.30 & & \\
\hline 30 to 34 years old & 4 & 3 & 7 & 2.59 & & \\
\hline 35 to 39 years old & 2 & 0 & 2 & 0.74 & & \\
\hline \multicolumn{7}{|l|}{ Race } \\
\hline Black or African American & 8 & 28 & 36 & & & \\
\hline Asian/Pacific Islanders & 40 & 56 & 96 & 35.56 & & \\
\hline White & 20 & 19 & 39 & 14.44 & & \\
\hline Hispanic or Latino & 37 & 43 & 80 & 29.63 & & \\
\hline Native American & 0 & 0 & 0 & 0 & & \\
\hline Other & 8 & 11 & 19 & 7.04 & & \\
\hline \multicolumn{7}{|l|}{ Current Marital Status } \\
\hline Single, never married & 106 & 153 & 259 & 95.93 & & \\
\hline Married or domestic partnership & 7 & 1 & 8 & 2.96 & & \\
\hline Widowed & 0 & 1 & 1 & 0.37 & & \\
\hline Divorced & 0 & 0 & 0 & 0 & & \\
\hline Separated & 0 & 2 & 2 & 0.74 & & \\
\hline \multicolumn{7}{|l|}{ Degree Program } \\
\hline Undergraduate & 105 & 147 & 252 & 93.33 & & \\
\hline Graduate & 7 & 8 & 15 & 5.56 & & \\
\hline Other & 1 & 2 & 3 & 1.11 & & \\
\hline
\end{tabular}

As shown in Table 2, the body mass index (BMI) mean of the respondents was 24.50 , a little over a third of the participants tended to follow no specific diet, while the rest followed several different dietary practices with the most frequent being high protein diets $(16 \%)$. Alarmingly, $21 \%$ of the sample reported use of disturbing weight loss practices, i.e., vomiting, starvation, and laxatives (see Table 2). These behaviors can be seen as reflective of undiagnosed disordered eating practices.

The participants' majors in this study were spread over the University's various colleges; College of Business Administration (9.63\%), College of Health and Human Services (30.37\%), College of Liberal Arts (24.07\%), College of Natural Sciences and Math (9.63\%), College of Education (15.93\%), and College of The Arts (7.78\%). Seven participants $(2.59 \%)$ declined to identify a college. There were no significant associations or correlations among the participants' habits of alcohol use, smoking, specific diet adherence, presence or lack of food allergies, whether or not they exercised, marital status, religious based diet restriction and prevalence of ON behaviors and/or OCD behaviors. Like-

Published by Sciedu Press wise, gender and BMI had no association or correlation with the prevalence of ON/OCD behaviors. However, it must be noted that the mean BMI of this entire sample was $24.5 \%$ without much variation (24.2 for males and 24.8 for females).

In this sample of college students, the prevalence rate of orthorexia behaviors was $37 \%$ while the prevalence rate of obsessive compulsive behaviors was $38.5 \%$. The mean score on the ORTO-15 was 42.29 with a mean standard deviation of 5.8; 100 participants scored less than 40 on the ORTO- 15 . Nearly two thirds $(65 \%)$ of these respondents who scored below 40 were female. In this study, the overall Cronbach Alpha for the ORTO- 15 was 0.74 ; in an acceptable range. The mean score on OCI-R was 18.71 , with a standard deviation of 12.6; 104 participants scored greater than 20 indicating obsessive compulsive behaviors. Nearly half (46\%) of these respondents were male.

As illustrated in Table 3, a major focus of this study was on participants who scored less than 40 on ORTO- 15 and $\geq$ 20 on OCI-R. The percentage of respondents who met the criteria for having both $\mathrm{ON}$ and $\mathrm{OC}$ behaviors was $38.52 \%$ $(\mathrm{N}=104)$. 
Table 2. Health characteristics and practices of participants by gender

\begin{tabular}{|c|c|c|c|c|}
\hline Variable & $\begin{array}{l}\text { Male } \\
(\mathrm{N}=113)\end{array}$ & $\begin{array}{l}\text { Female } \\
(\mathrm{N}=157)\end{array}$ & $\begin{array}{l}\text { Total } \\
(N=270)\end{array}$ & $\begin{array}{l}\text { Cumulative } \\
\text { Percentage }\end{array}$ \\
\hline \multicolumn{5}{|l|}{ Smoking status } \\
\hline Yes & 21 & 16 & 37 & 13.7 \\
\hline No & 91 & 141 & 232 & 86.3 \\
\hline \multicolumn{5}{|l|}{ Alcohol } \\
\hline Yes & 57 & 89 & 146 & 54.07 \\
\hline No & 55 & 68 & 123 & 45.93 \\
\hline \multicolumn{5}{|l|}{ Specific Diet } \\
\hline No specific diet & 49 & 51 & 100 & 37.00 \\
\hline High protein & 26 & 18 & 44 & 14.8 \\
\hline Vegan & 2 & 2 & 4 & 1.48 \\
\hline Vegetarian & 3 & 15 & 18 & 6.66 \\
\hline Gluten Free & 1 & 2 & 3 & 1.11 \\
\hline Low Sodium & 6 & 14 & 20 & 7.41 \\
\hline Pescatarian & 3 & 13 & 16 & 5.92 \\
\hline Low Calorie & 6 & 13 & 19 & 7.03 \\
\hline Low Carbohydrate & 9 & 19 & 28 & 10.57 \\
\hline Other & 8 & 10 & 18 & 6.66 \\
\hline \multicolumn{5}{|l|}{ Food Allergy } \\
\hline Yes & 16 & 23 & 39 & 14.44 \\
\hline No & 96 & 134 & 230 & 85.55 \\
\hline \multicolumn{5}{|l|}{ Dietary Restrictions (Religious) } \\
\hline Yes & 3 & 5 & 8 & 2.97 \\
\hline No & 109 & 151 & 260 & 97.3 \\
\hline \multicolumn{5}{|l|}{ Exercise } \\
\hline Yes & 97 & 116 & 213 & 78.89 \\
\hline No & 16 & 41 & 57 & 21.11 \\
\hline \multicolumn{5}{|l|}{ Weight Loss Practices } \\
\hline \multicolumn{5}{|l|}{ Vomiting } \\
\hline Yes & 1 & 9 & 10 & 3.70 \\
\hline No & 111 & 148 & 259 & 96.3 \\
\hline \multicolumn{5}{|l|}{ Starvation } \\
\hline Yes & 10 & 24 & 34 & 12.60 \\
\hline No & 102 & 133 & 235 & 87.4 \\
\hline \multicolumn{5}{|l|}{ Use of Laxatives } \\
\hline Yes & 3 & 11 & 14 & 5.18 \\
\hline No & 109 & 145 & 254 & 94.82 \\
\hline Body Mass Index (BMI) Mean & 24.2 & 24.8 & 24.5 & \\
\hline
\end{tabular}

Table 3. Participants with ORTO- 15 scores $<40$ and OCI-R scores $>20$

\begin{tabular}{lllll}
\hline \multirow{2}{*}{ OCI-R } & \multicolumn{2}{l}{ ORTO-15 } & & \\
\cline { 2 - 5 } & No (N) & Yes $(\mathbf{N})$ & Total $(\mathbf{N})$ & Total \% \\
\hline No $(\mathrm{N})$ & 124 & 42 & 166 & $61.48 \%$ \\
Yes (N) & 46 & 58 & 104 & $38.32 \%$ \\
Total & 170 & 100 & 270 & $100 \%$ \\
\hline$\chi^{2}$ : DF 1 Value $25.45 ; p \leq .0001$ & &
\end{tabular}

As shown in Table 4, Pearson's $r$ correlation showed a strong negative correlation $(p<.001)$ between ORTO-15 scores and the OCI-R subscale scores. As the scores on the OCI-R subcategories went up (indicating more obsessive-compulsive behavior), the scores on the ORTO-15 went down (indicating more orthorexia nervosa behavior).

As illustrated in Table 5, the results of an analysis of variance (ANOVA) demonstrated that three sub-categories of the OCI-R (neutralizing, obsessing, and ordering) significantly contributed to the observed variance $(\mathrm{F}=14.69 ; p<.0001)$ 
on the ORTO-15. Participants with orthorexic tendencies, whose scores did not reflect orthorexic tendencies (point i.e., scoring below the cut off score of 40 on the ORTO-15, estimate 3.73, Wald 95\% confidence limits: 2.209 to 6.27). had greater odds to score $\geq 20$ on the OCI-R than those

Table 4. Pearson's $r$ : Correlations between ORTO-15 scores and OCI-R sub-category scores ( $\mathrm{N}=270)$

\begin{tabular}{lllllll}
\hline OCI-R sub-scale & Checking & Hoarding & Neutralizing & Obsessing & Ordering & Washing \\
\hline Correlation $(r)$ & $-0.318^{*}$ & $-0.235^{*}$ & $-0.313^{*}$ & $-0.299^{*}$ & $-0.298^{*}$ & $-0.293^{*}$ \\
\hline${ }^{*} p<.001$ & & & & &
\end{tabular}

Table 5. Sub-categories of the OCI-R contributing the most variance to the ORTO- 15 score $(\mathrm{N}=270)$

\begin{tabular}{llll}
\hline OCI-R sub scale & Neutralizing & Obsessing & Ordering \\
\hline F value & 4.82 & 5.27 & 5.50 \\
$p$ & $.029^{*}$ & $.022^{*}$ & $.019 *$ \\
\hline
\end{tabular}

Note. ANOVA: DF 3; F value 14.69; *significant at the .05 level.

\section{DISCUSSION AND CONCLUSION}

This investigation was done to determine the prevalence of orthorexia behaviors and obsessive-compulsive behaviors among university students. Previous studies indicated this population was at risk for these behaviors. ${ }^{[3,4,11]}$ The prevalence rates from this study (ON behaviors $37 \%$ and OC behaviors 38\%) are consistent with previous studies. While this prevalence is not as high as is found in some of the previous studies, it appears to be higher than would be expected among the general population. ${ }^{[9]}$ College/university students have increased stress and anxieties about life changes that occur with college matriculation and this could account for higher numbers and kinds of behavioral changes seen among this population. This study confirmed that college/university students are a high-risk population for orthorexic and obsessive behaviors. Perhaps as a preventative measure, colleges and universities could enrich their orientation programs to include information about recognizing early disordered eating behaviors and obsessive behaviors related to nutrition, including information about campus and community resources for students to obtain more information or early intervention services.

Interestingly, many of the previous studies regarding ON and OCD behaviors had a majority of Caucasian participants in their samples which lead them to speculate that race and culture might have had an impact on their findings. The sample in this study was $65 \%$ Asian or Hispanic and only $14 \%$ Caucasian, which by comparison, was unique. However, the findings were still consistent with those of previous studies in term of ON and OCD behavior prevalence. Similar to other studies, the sample in this study had more females (58\%) than males $(42 \%)$. Considering the fact that participants were volunteers without any incentivizing, females might

Published by Sciedu Press have found the subject matter of more interest to them than it was to males.

This study had the additional goal of determining whether or not a correlation existed between OCD and ON symptoms. It was determined that individuals with $\mathrm{ON}$ behaviors, were statistically higher than the participants without ON behaviors to also have OCD behaviors. However, individuals who had OCD symptoms were not as likely to also exhibit ON symptoms. In this study, a strong, negative correlation was found between the participants' scores on the ORTO-15 and their scores on the OCI-R thus, confirming that a correlation does exist. The finding is consistent with that of other studies. ${ }^{[4,13]}$

The finding of a correlation between the scores on the ORTO15 and the OCI-R among the participants of this study may mean that ON symptoms and OCD symptoms are co-morbid. Or perhaps it may mean that a person with $\mathrm{ON}$ tendencies, at some point of time, may evolve to include OCD symptomatology. This finding also supports the speculations of other researchers that $\mathrm{ON}$ shares similar patterns with $\mathrm{OCD}$, that ON driven concerns for health may prompt a person to develop routine, repetitive behaviors/actions and, $\mathrm{ON}$ behaviors may ultimately lead to ODC..$^{[5,16,18]}$

However, it must be noted that those participants who were already obsessive (demonstrating hoarding, neutralizing, washing, checking, ordering behaviors) were not as likely to become obsessed with adding, yet, another thing (healthy, pure lifestyles and healthy, clean, pure foods) to their current repertoires. The findings in this study suggest that individuals who are expressing OCD behaviors are less likely to express ON behaviors. Using the information from the study, one can make a tentative, hypothetical statement that $\mathrm{ON}$ tendencies may provoke OCD tendencies.

\subsection{Limitations}

This study had various limitations. One limitation was the assumption that all participants responded honestly on the surveys. Another limitation was that there was no attempt to assess the influence of media, social norms, and peer influence on the participants' own definition of "clean", "pure", 
"healthy" eating. The current study used a sample from a single university in California; a state where healthy eating is highly promoted and food varieties are relatively available during all seasons of the year. Finally, the results of this study cannot be generalized to the general population due to the fact that the participants were young adults.

\subsection{Implications for practice, conclusion, and recom- mendations}

Nurses can ask more detailed questions of patients who present with nutritional deficiencies or who describe an inability to tolerate changes to their eating behaviors. These questions can focus on the preparation of meals, the pattern of eating, and the feelings associated with eating including feelings of guilt, control, or isolation. Mental health nurses can utilize the therapeutic relationship to target the patient's ability to identify and verbalize emotions surrounding eating patterns. It this way the psychoeducation of clients can help individuals to work though underlying conflicts, increase distress tolerance, and decrease isolation. ${ }^{[29]}$

If mental health professionals who encounter clients with orthorexic tendencies are aware of the overlap and correlation with OCD behaviors, it could prompt additional screening and possible detection of co-morbid obsessive-compulsive disorder. Awareness that college/university students pose a high-risk group for $\mathrm{ON}$ tendencies may encourage colleges and universities to disseminate information regarding awareness, prevention, early symptom recognition as well as availability of assistance through student health centers on their campuses.
This can be in the form of student education pamphlets regarding eating disorders, perceptions of body image, and screening questions regarding eating behaviors. General questions regarding this type of information can also routinely be included in a general health questionnaire completed by patients. This would allow nurses to better recognize possible eating disorders in their patients. ${ }^{[30]}$

Additionally, several studies including this one, have reported that $\mathrm{ON}$ behaviors are more prevalent in females than in males. Such gender differences might imply, through future research, that women's ON patterns are somewhat influenced by society's standards, or mass media, or perhaps such an idealized body image that women feel compelled to follow so-called healthy, but in reality, unhealthy eating. More research is needed to develop a better screening tool for orthorexia that can be validated and reliable to detect ON. Future research is needed to identify high risk groups other than college/university students and females and to add more data on orthorexia nervosa so that the debate can be resolved on whether $\mathrm{ON}$ is a separate eating disorder or just a variant of the OCD spectrum, or a variant of anorexia nervosa.

\section{ACKNOWLEDGEMENTS}

The authors would like to acknowledge the help of Hannah Gross, Lea Ann Gomez, Crystal Nguyen, and Loretta Lyken in the acquisition of data for this study.

\section{CONFLicts OF INTEREST Disclosure}

The authors declare that there is no conflict of interest.

\section{REFERENCES}

[1] Costa CB, Hardan-Khalil K, Gibbs K. Orthorexia nervosa: a review of the literature. Issues in Mental Health Nursing. 2017; 38(12): 980988. PMid:29215937 https://doi.org/10.1080/01612840.2 017.1371816

[2] Bratman S. Health food junkie. Yoga Journal. 1997; 42-50.

[3] Oberle CD, Samaghabadi RO, Hughes EM. Orthorexia nervosa: assessment and correlates with gender, BMI, and personality. Appetite 2017; 108: 303-310. PMid:27756637 https ://doi .org/10.101 6/j.appet.2016.10.021

[4] Dell'Osso L, Carpita B, Muti D, et al. Prevalence and characteristics of orthorexia nervosa in a sample of university students in Italy. Eat Weight Disorders. 2018; 23: 55-65. PMid:29134507 https ://doi.org/10.1007/s40519-017-0460-3

[5] OCD Center of LA. Orthorexia: where eating disorders meet OCD, OCD Center of Los Angeles. 2011. Available from: https : //ocdl a. com/orthorexia-eating-disorders-ocd-1977

[6] Nevin SM, Vartanian LR. The stigma of clean dieting and orthorexia nervosa. Journal of Eating Disorders. 2017; 5(37): 1-10. PMid:28053702
[7] Bratman S. What is orthorexia? Available from: http://www . orth orexia.com/what-is-orthorexia/

[8] Koven N S, Abry AW. The clinical basis of orthorexia nervosa: emerging perspectives. Neuropsychiatric Disease and Treatment. 2015; 11 : 385-394. PMid:25733839

[9] Dunn TM, Gibbs J, Whitney N, et al. Prevalence of orthorexia nervosa is less than 1\%: Data from a US sample. Eat Weight Disord. 2017; 22(1): 185-192. PMid:26902744 https://doi.org/10.1 007/s40519-016-0258-8

[10] Ramacciotti C, Perrone P, Coli E, et al. Orthorexia nervosa in the general population: a preliminary screening using a self-administered questionnaire (ORTO-15). Eat and Weight Disorder. 2011; 16(2): e127-e130.

[11] Bundros J, Clifford D, Silliman K, et al. Prevalence of orthorexia nervosa among college students based on Bratman's test and associated tendencies. Appetite. 2016; 101: 86-94. PMid:26923745 https : //doi.org/10.1016/j.appet.2016.02.144

[12] Mancebo M, Eisen J, Grant J, et al. Obsessive compulsive personality disorder and obsessive compulsive disorder: clinical characteristics, diagnostic difficulties, and treatment. Annals Clinical Psychiatry. 
2005; 17(4): 197-204. PMid:16402751 https://doi.org/10.1 080/10401230500295305

[13] Moroze RM, Dunn TM, Holland C, et al. Microthinking about micronutrients: a case of transition from obsessions about healthy eating to near-fatal "orthorexia nervosa" and proposed diagnostic criteria. Psychosomatics. 2015; 56: 397-403. PMid:25016349 https://doi.org/10.1016/j.psym.2014.03.003

[14] Murphy R, Nutzinger DO, Paul T, et al. Conditional-Associative learning in eating disorders: a comparison with OCD. Journal of Clinical and Experimental Neuropsychology. 2004; 26(2): 190199. PMid:15202539 https://doi.org/10.1076/jcen.26.2. 190. 28091

[15] Neziroglu F. The relationship between eating disorders and OCD part of the spectrum. International OCD Foundation. 2017. Available from: https://iocdf.org/expert-opinions/expert-opini on-eating-disorders-and-ocd/

[16] Brytek-Matera A. Orthorexia nervosa - an eating disorder, obsessive -compulsive disorder or disturbed eating habit? Archives of Psychiatry and Psychotherapy. 2012; 1: 55-60. Available from: http://www.archivespp.pl/uploads/images/2012_ 14_1/BrytekMatera55__APP1_2012.pdf

[17] Poyraz C, Ozdemir A, Tufekcioglu E. Relationship between orthorexia and obsessive-compulsive symptoms in patients with generalized anxiety disorder, panic disorder and obsessive compulsive disorder. NYS. 2015; 53(4): 22-26. Available from: https://www.researchgate.net/publication/301235291 _Relationship_between_orthorexia_and_obsessive-com pulsive_symptoms_in_patients_with_generalised_anxi ety_disorder_panic_disorder_and_obsessive_compulsi ve_disorder

[18] Altman SE, Shankman SA. What is the association between obsessive-compulsive disorder and eating disorders? Clinical Psychology Review. 2009; 29(7): 638-646. PMid:19744759 https: //doi.org/10.1016/j.cpr.2009.08.001

[19] Scarff J. Orthorexia Nervosa: an obsession with healthy eating. Fed Pract. 2017 June; 34(6): 36-39.

[20] Donini LM, Marsili D, Graziani MP, et al. Orthorexia nervosa: a preliminary study with a proposal for diagnosis and an attempt to measure the dimension of the phenomenon. Eat Weight Disorders. 2004; 9(2): 151-157. https://doi .org/10.1007/BF03325060

[21] Donini LM, Marsili D, Graziani MP, et al. Orthorexia nervosa: validation of a diagnosis questionnaire. Eat Weight Disorders. 2005; 10(2): e28-32.

[22] Chaki B, Pal S, Bandyopadhyay A. Exploring scientific legitimacy of orthorexia nervosa: a newly emerging eating disorder. Journal of Human Sport and Exercise. 2013; 4(8): 1045-1053. https: //doi.org/10.4100/jhse.2013.84.14

[23] Varga M, Thege BK, Dukay-Szabo S, et al. When eating healthy is not healthy: orthorexia nervosa and its measurement with the ORTO15 in Hungary. BMC Psychiatry. 2014; 14: 59. PMid:24581288 https://doi.org/10.1186/1471-244X-14-59

[24] Brytek-Matera A, Donini LM, Krupa M, et al. Orthorexia nervosa and self-attitudinal aspects of body image in female and male university students. Journal of Eating Disorders. 2015; 3(2).

[25] Brytek-Matera A, Krupa M, Poggiogalle E, et al. Adaptation of the ORTHO-15 test to Polish women and men. Eat Weight Disorders 2014; 19(1): 69-76. PMid:24448996 https://doi.org/10.100 7/s40519-014-0100-0

[26] Foa EB, Huppert JD, Leiberg S, et al. The Obsessive-Compulsive Inventory: development and validation of a short version. Psycholgical Assessment. 2002; 14(4): 485-496. https://doi.org/10.1037/ 1040-3590.14.4.485

[27] Abramowitz JS, Deacon BJ. Psychometric properties and construct validity of the Obsessive-Compulsive Inventory-Revised: replication and extension with a clinical sample. Journal of Anxiety Disorders. 2006; 20(8): 1016-1035. PMid:16621437 https://doi .org/10.1 016/j.janxdis. 2006.03.001

[28] Hajcak G, Huppert JD, Simons RF, et al. Psychometric properties of the OCI-R in a college sample. Behaviour Research and Therapy. 2004; 42(1): 115-123. https://doi.org/10.1016/j.brat. 200 3.08 .002

[29] Morin K. When healthy eating is carried to the extreme. MCN, The American Journal of Maternal/Child Nursing. 2017; 42(3): 181.

[30] Hepworth K. Eating disorders today-Not just a girl thing. Journal of Christian Nursing. July-September 2010; 27(3): 236-241. 